\title{
REVIEW
}

\section{Penile reconstruction}

\author{
Giulio Garaffa ${ }^{1}$, Salvatore Sansalone ${ }^{2}$ and David J Ralph ${ }^{1}$
}

During the most recent years, a variety of new techniques of penile reconstruction have been described in the literature. This paper focuses on the most recent advances in male genital reconstruction after trauma, excision of benign and malignant disease, in gender reassignment surgery and aphallia with emphasis on surgical technique, cosmetic and functional outcome. Asian Journal of Andrology (2013) 15, 16-19; doi:10.1038/aja.2012.9; published online 19 March 2012

Keywords: female to male transsexuals; fibrosis; free flaps; glans reconstruction; glans sculpture; lichen sclerosus; lymphoedema of the genitalia; penile prosthesis; Peyronie's disease; phalloplasty; scrotoplasty; shaft reconstruction; skin graft; penile reconstruction

\section{INTRODUCTION}

Although over the past decades, reconstructive surgery of the penis has steadily continued to evolve, repairing and reconstructing the penis remains anatomically, functionally and aesthetically a great challenge. This is because the primary goal of penile reconstruction surgery is the achievement of a cosmetically acceptable phallus with incorporated neo-urethra, which allows the patient to void while standing from the tip of the phallus in a male urinal, and enough bulk to house the cylinder(s) of an inflatable penile prosthesis to guarantee enough rigidity for penetrative sexual intercourse.

Ideally, in penile trauma, avulsion, partial or complete excision, surgical repair should be immediate with preservation of as much viable tissue as possible, since no other tissue in the body has characteristics, in terms of elasticity, texture and colour, to match adequately genital skin, tunica albuginea, spongiosum and cavernosum. When primary repair with genital tissue is not feasible, reconstruction can be achieved with the use of skin grafts or a variety of pedicled and free flaps.

A non-structured review of the most recent English literature on glans, penile and scrotal reconstruction, and total phallic reconstruction in case of amputation, aphallia or gender dysphoria has been carried out.

\section{GLANS RECONSTRUCTION}

Reconstruction of the glans in isolation is required following traumatic amputation or surgical excision of benign and malignant conditions.

Surgical procedures involving partial or complete excision of the glans and their indications are reported in Table 1. Glans reconstruction may also become necessary following traumatic amputation of the glans or the distal corpora.

Glans resurfacing is indicated in patients with lichen sclerosus or carcinoma in situ of the glans penis and involves the partial or complete excision of the glans mucosa followed by repair with the use of a split thickness graft (STG) usually harvested from the inner thigh. ${ }^{1,2}$
If only a small portion of the mucosa of the glans is affected by lichen sclerosus or carcinoma in situ, patients can be offered a partial glans resurfacing with excision only of the involved mucosa followed by repair with the use of STG. STGs tend to take better than their full thickness counterpart on the denuded spongy tissue and excellent cosmetic and functional results have been reported in almost all cases. ${ }^{2}$

Partial glansectomy instead is indicated if only a small portion of the glans is affected by squamous cell carcinoma of the penis. In these patients, a wedge including the affected aspect of the glans is excised down to the tunica albuginea in order to achieve adequate clearance and reconstruction is achieved by primary closure of the defect.

Patients with widespread pT1 and pT2 squamous cell carcinoma of the glans penis are instead better served with a glansectomy, which involves the complete excision of the spongiosum of the glans penis that is dissected off the tip of the corpora cavernosa just above the tunica albuginea. ${ }^{3}$ Glans reconstruction is then achieved either with the use of an STG, which is applied on the denuded corporeal heads, or with a urethral flap, which is spatulated, inverted and reshaped in a 'pseudo-glans' fashion ${ }^{4,5}$ (Figure 1).

Alternatively, glans and coronal reconstruction can be also achieved with the use of urethral, rectus abdominis or palmaris longus flaps. ${ }^{6,7}$ Although the results are satisfactory, only few case reports have been described in the literature, and therefore, a larger series will be necessary to confirm the reliability of these techniques for glans reconstruction.

Glans reconstruction following glansectomy and distal corporectomy is a simple and reproducible procedure. Complications include poor graft take requiring regrafting in around $6 \%$ of patients and inadequate final cosmetic or functional outcome in $1 \%$ of cases in patients who have undergone reconstruction with the use of skin grafts. ${ }^{3}$ The only complication reported in patients who have undergone reconstruction with the use of inverted urethral flaps is minor ventral penile curvature, which occurs in $10 \%$ of cases and is consequence of a relatively short urethra acting as a bowstring during erections. ${ }^{4,5}$ Overall, almost all patients retain sexual and urinary 
Table 1 Surgical procedures involving partial or complete excision of the glans and their indications

\begin{tabular}{ll}
\hline Procedure & Indication \\
\hline Glans resurfacing & Lichen sclerosus, Carcinoma in Situ \\
Partial glansectomy & Carcinoma of the penis \\
Total glansectomy & Carcinoma of the penis \\
Distal corporectomy & Carcinoma of the penis \\
\hline
\end{tabular}

function and are reported to be already engaging in satisfactory penetrative sex 3 months postoperatively. ${ }^{8}$

\section{SCROTAL RECONSTRUCTION}

Loss of scrotal skin may be consequence of necrotizing fascitis, trauma or following excision of bulky penile tumours. The laxity of the scrotal skin allows for primary closure even in skin losses of up to $50 \% ;{ }^{9}$ when primary closure is not feasible, reconstruction of the scrotum can be achieved using either STG or local myocutaneous and fasciocutaneous flaps.

The primary concern when repairing scrotal defects is testicular protection in order to prevent damage to the spermatogenesis. Testicular insult can be initially minimized with the use of wet dressing; alternatively, the testes can be temporarily positioned in subcutaneous thigh pouches. Although thigh pouches represent a good short-term solution, relocation of the testes in a more anatomic position is supported by concerns about pain, adverse psychological outcomes and thermoregulation. With regards to thermoregulation, Wang et al. ${ }^{10}$ have reported that spermatogenesis is significantly abnormal at 2 years' follow-up in patients with testicles buried in thigh pouches and therefore, thigh pouches are not recommended as a long-term solution in patients who whish to preserve fertility.

Usually scrotal reconstruction is performed with the use of meshed STG; however, an adequate graft take is possible only if tunica vaginalis and granulation tissue are present at the time of grafting.

Adequate preparation of the recipient site for grafting is paramount in order to achieve an adequate cosmetic and functional result and the spermatic cord and testicles should be sutured together along the midline to minimize the grafting area and to prevent the creation of a bifid neoscrotum. ${ }^{11}$

Meshed STGs are a good solution for scrotal repair, since they allow the drainage of exudate through the fenestrations, thus improving the success of graft take to nearly $100 \%$. Moreover, when healed, they mimic the rugae that normally characterize the scrotal skin.

However, STGs are insensate, demand a long and time-consuming period of wound care, and play no role in the thermoregulation of the scrotal content; therefore, local pedicled flaps are the preferred option for providing testicular coverage, when the remnant scrotal tissue is insufficient for primary closure. The use of local flaps is not associated with the typical complications of skin grafts such as skin maceration, poor take and breakdown secondary to faecal and urinary contamination and requires less intense postoperative care.

Classically, the vertical rectus abdominis myocutaneous flap yields the best cosmetic and functional results, but is also associated with significant donor site morbidity. Other myocutaneous and fasciocutaneous flaps based on tissue from the perineum, groin and lower limbs have been described. Among these, the medial circumflex femoral artery perforator flap, the gracilis myofasciocutaneous flap, the neurovascular pedicled pudendal thigh flap and the Singapore flap are the most commonly used. ${ }^{12}$

\section{PENILE SHAFT RECONSTRUCTION}

For simplicity, penile reconstruction can be subdivided in repair of skin loss alone or reconstruction of the corpora cavernosa.

Genital skin loss is usually consequence of trauma, necrotizing fascitis, excision of benign and malignant lesions, excessive circumcision, previous hypospadias or epispadia surgery, animal bites and burns. ${ }^{13-19}$

Since the use of scrotal flaps for penile skin defect cover is associated to poor cosmetic results due to the different skin texture and colour and the presence of hairs, skin grafts still represent the solution of choice.

Although various authors use meshed and non-meshed STGs for penile shaft cover due to their ease of harvesting, and superior take rate, full thickness skin grafts (FTGs) tend to heal with less contracture and maintain a more significant degree of elasticity. ${ }^{18,19}$ Therefore, FTGs harvested from non-hair bearing areas of the body should be the solution of choice in patients who have good quality erection, are concerned with cosmetic outcome and wish to resume penetrative sexual activity.

Reconstruction of the corpora cavernosa is instead required in female to male transsexuals and in all cases of penile inadequacy, including aphallia, micropenis, amputation and short penis postrepeated explantation of infected penile prosthesis. ${ }^{20}$

Due to the unique anatomy of the penis, penile preservation should be always attempted leaving total phallic reconstruction as a last resort. Therefore, patients who have suffered partial amputation of the penis and potentially present still a reasonable penile length are initially offered conservative management such as division of the suspensory ligament or excision of the suprapubic fat pad in order to maximize the length of the penile stump. Patients presenting with severely contracted corpora cavernosa following repeated explantation of infected penile prosthesis should instead be offered simultaneous total corporeal reconstruction and penile prosthesis implantation as this technique yields good results in expert hands. ${ }^{21}$ This procedure is indicated only if the contracture of the tunica albuginea is so severe that, after adequate dilatation of the corpora, the corporotomies cannot be closed even on downsized cylinders. In particular, in a series of eight patients managed with simultaneous total corporeal reconstruction with the use of rectus fascia graft and penile prosthesis implantation, Patak et al. ${ }^{21}$ reported no complication after a median follow-up of 18 months (Figure 2).

Total phallic reconstruction should be offered only if all conservative measures fail and the patient is not capable to resume penetrative sexual intercourse and to void while standing, or in presence of severe psychological distress.

The complex anatomy and physiology of the penis and the fact that there is no good substitute for the unique erectile tissue of the corpora represent the main obstacles for the reconstructive surgeon and despite a variety of surgical techniques have been described in the literature, none still fulfils all the criteria and is currently universally accepted as the ideal method. ${ }^{22-24}$

The choice of the reconstructive technique should be tailored on patients' expectations, body habitus and previous surgical procedures, since thigh and forearm free flaps are associated with poorer cosmetic result in obese patients due to the excessive thickness of the adipose layer and transverse lower abdominal scars may contraindicate the use of infraumbilical flaps. Also patients' comorbidities must be taken into account, since diabetes, hypertension, dyslipidaemia, obesity and cigarette smoke are associated with high risk of vascular complications and therefore, represent relative contraindication to the use of free flaps. 

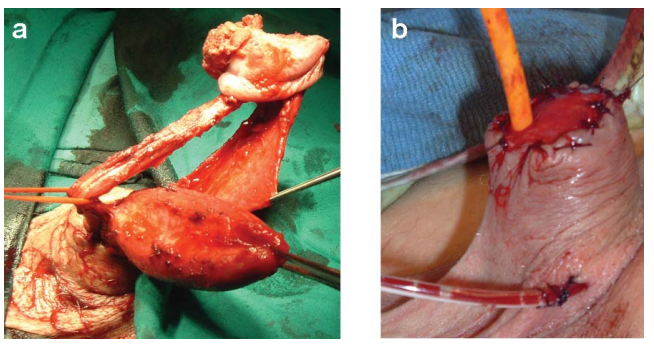

Figure 1 Glansectomy followed by reconstruction with the use of urethral flaps. (a) The glans penis is excised and the entire penile urethra is dissected off the corpora cavernosa in order to gain enough length to be spatulated on the top of the denuded corpora to form a pseudoglans. (b) The final result. The spatulated urethral flap is bent backward to feature the pseudoglans.

Patients must be fully counselled about the pros and cons of each type of phalloplasty and must have reasonable expectations. Patients desired goals in terms of size, sensation, sexual and voiding function also play an important role in the selection of the type of flap as sensation and a patent neo-urethra can be achieved only with some techniques. Finally, donor site morbidity, as well as the number of surgical stages necessary to complete the phalloplasty, must be taken into consideration.

After many disappointing attempts with the use of infraumbilical flaps and musculocutaneous thigh flaps based on the gracilis muscle, the advent of microsurgical techniques has led to a new era for total phallic reconstruction. ${ }^{25}$ Although no controlled prospective randomized studies are available to confirm that the radial artery free flap phalloplasty (RAFF) is the best technique available, most authors consider that it is extremely reliable and yields excellent cosmetic and functional results in very experienced hands. ${ }^{26-33}$ This procedure involves the creation of 'a tube within a tube' using forearm skin with the urethra fashioned from the non-hair bearing area and the whole flap based on the radial artery. Sensation is maintained due to the coaptation of the antebrachial nerves to the dorsal nerve of the penis in the male or of the clitoris in the female to male transsexual and to the iliohypogastric and ilioinguinal nerves.

Overall patients' satisfaction with this technique can be as high as $97 \%$ with phallic sensation present in up to $86 \%$ of cases. ${ }^{29}$ The most feared complication is acute thrombosis of the microsurgical anastomosis; this complication, if not identified and managed immediately leads invariably to the loss of the phallus. Although urethral complications such as strictures and fistulas can occur in around $30 \%$ of cases, correction is almost always possible and up to $99 \%$ of patients have been reported able to void standing from the tip of the phallus after revision surgery. ${ }^{29}$

Implantation of an erectile device to guarantee the rigidity necessary for penetrative sexual intercourse is usually carried out at least 1 year after the creation of the phalloplasty, when phallic sensation is likely to have developed. Due to the unique anatomy of the phallus and the absence of the tunica albuginea, complication such as infection of the device, erosion and mechanical failure are common in patients with phalloplasty. In a recent series of 129 patients with phalloplasty who have undergone implantation of an erectile device, infection rate, erosion rate and mechanical failure of the device were respectively $11.9 \%, 8.1 \%$ and $22.2 \%$, and revision has been necessary in $41 \%$ of cases. Overall, after a median follow-up of 30.3 months, up to $60 \%$ of patients had a normally functioning penile prosthesis and were able to cycle the device. $^{34}$

If the original glans is present, it can be transferred with microsurgical technique to the distal aspect of the RAFF in order to improve cosmesis and sensation. In a series of 27 patients, after a median follow-up of 10.3 years, Cheng et al. ${ }^{35}$ reported that all flaps had survived and that the sensation of the transposed glans was similar to the one assessed preoperatively.

The main drawback of RAFF is donor site morbidity; although this can be dramatically reduced by adequate preparation of the donor site for grafting and with the use of hair bearing FTGs instead of their spit thickness counterpart, the resulting scar represents a stigma and can be poorly accepted by patients.

Despite free osteocutaneous fibular flaps, anterolateral thigh flaps, latissimus dorsi flap and upper arm flaps have been introduced in order to minimize donor site morbidity, they are associated with poorer cosmetic results than the RAFF phalloplasty. ${ }^{36-39}$

Therefore, patients who whish to void from the tip of the phallus but do not accept a wide scar on the donor forearm can be offered the incorporation of a radial artery-based free flap urethra in a phallus previously fashioned with an infraumbilical flap. This technique is very reproducible in experienced hands and yields excellent cosmetic and functional results with all patients able to void standing from the tip of the phallus after revision surgery. Since the flap required is only $4 \mathrm{~cm}$ wide, the resulting scar can be easily masked and therefore, is more acceptable by the patients. ${ }^{40}$
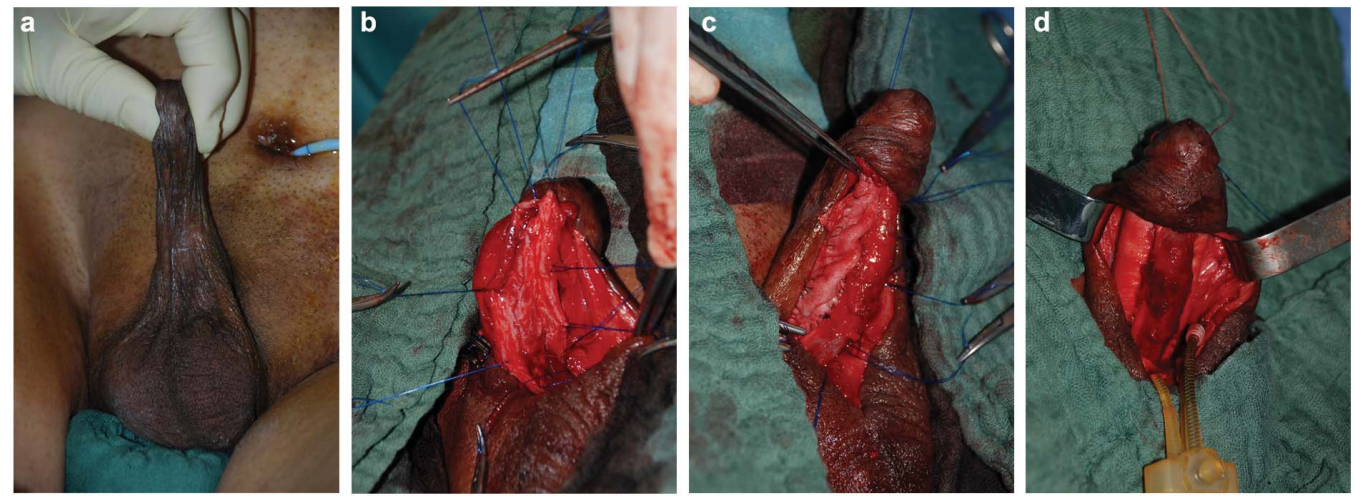

Figure 2 Simultaneous corporeal reconstruction and penile prosthesis implantation in patients with penile inadequacy and severe corporeal fibrosis and contracture following repeated explantation of infected penile prosthesis. (a) The corpora are contracted and diffusely fibrotic. (b) A midline longitudinal incision of the penile skin is performed and the corpora exposed. Two longitudinal paraurethral corporeal incisions are carried out and the fibrotic tissue excised. (c) The corpora are reconstructed with the use of two longitudinal grafts. (d) The cylinders of a three pieces inflatable penile prosthesis are inserted in the reconstructed corpora cavernosa. 


\section{CONCLUSIONS}

Skin grafts still represent the solution of choice for repair of skin defects on the glans and shaft penis. STGs tend to be easier to harvest and to take better than their full thickness counterpart; however, they are associated with a higher degree of contracture and therefore, are ideal only for glans reconstruction. Full thickness grafts are the solution of choice on the shaft as they heal maintaining the elasticity necessary to achieve adequate erections. Meshed skin grafts are associated with poor cosmetic results and their use should be limited only to the scrotum.

In scrotal skin defects, when primary closure is not feasible, local flaps are the solution of choice, as they tend to heal better than skin grafts and can play a role in thermoregulation of the testicles.

With regards to penile reconstruction, phalloplasty should be offered only when conservative measures have failed. Although none of the techniques of total phallic reconstruction is universally recognized as the gold standard, RAFF and its modifications yield the best cosmetic and functional results.

\section{COMPETING FINANCIAL INTERESTS}

The authors declare no competing financial interests.

1 Depasquale I, Park AJ, Bracka A. The treatment of balanitis xerotica obliterans. BJU Int 2000; 86: 459-65.

2 Hadway $\mathrm{P}$, Corbishley $\mathrm{CM}$, Watkin N. Total glans resurfacing for premalignant lesions of the penis: initial outcome data. BJU Int 2006; 98: 532-6.

3 Pietrzak P, Corbishley, Watkin N. Organ-sparing surgery for invasive penile cancer: early follow-up data. BJU Int 2004; 94: 1253-7.

4 Belinky JJ, Cheliz GM, Graziano CA, Rey HM. Glanuloplasty with urethral flap after partial penectomy. J Urol 2011; 185: 204-6.

5 Leonardi R, Pecoraro S, Silvani M, Zucchi A. Multicentric study of reconstructive technique of the glans after partial penectomy for squamous cell carcinoma. J Sex Med 2011; 8 (Suppl 5): 369-83.

6 Salgado CJ, Licata L, Fuller DA, Chen HC, Mardini S. Glans penis coronaplasty with palmaris longus tendon following total penile reconstruction. Ann Plast Surg 2009; 62: 690-2.

7 Shaeer O, EI Sebaie A. Construction of neoglans penis: a new sculpturing technique for rectus abdominis myofasical flap. J Sex Med 2005; 2: 259-65.

8 Morelli G, Pagni R, Mariani C, Campo G, Menchini-Fabris F et al. Glansectomy with split-thickness skin graft for the treatment of penile carcinoma. Int J Imp Res 2009; 21: 311-4.

9 Morey AF, Rozansky TA. Genital and lower urinary tract trauma. In: Wein AJ, Kavoussi LR, Novick AC, Partin AW, Peters CA, editors. Campbell-Walsh Urology. Philadelphia: Saunders Elsevier; 2007. p993-1022.

10 Wang D, Zheng H, Deng F. Spermatogenesis after scrotal reconstruction. Br J Plast Surg 2003; 56: 484-8.

11 Mutaf M, Isik D, Bulut O, Büyükgüral B. A true one-stage nonmicrosurgical technique for total phallic reconstruction. Ann Plast Surg 2006; 57: 100-6.

12 Salgado CJ, Monstrey S, Hoebeke P, Lumen N, Dwyer M et al. Recosntruction of the penis after surgery. Urol Clin N Am 2010; 37: 379-401.
13 Mokhless IA, Abdelaheim HM, Rahman A, Safwat A. Penile advancement and lengthening of post circumcision traumatic short penis in adolescents. Urology 2010; 76: 1483-7.

14 Barabas J, Kelemen Z, Banfi G, Nemeth Z, Romics I et al. Penis covering and simultaneous urethral replacement by scrotal skin for severe penile and urethral necrosis. Int Urol Nephrol 2009; 41: 537-40.

15 Tang SH, Kamat D, Santucci RA. Modern management of adult acquired buried penis. Urology 2008; 72: 124-7.

16 Ferreira PC, Reis JC, Amarante JM, Silva AC, Pinho CJ et al. Fournier's gangrene: a review of 48 reconstructive cases. Plast Reconstr Surg 2007; 119: 175-84.

17 Castro RB, Oliveira AB, Favorito LA. Utilization of skin flap for reconstruction of the genitalia after an electric burn. Int Braz J Urol 2006; 32: 68-9.

18 Black PC, Friderich JB, Engrav LH, Wessells H. Meshed unexpanded split thickness skin grafting for reconstruction of penile skin loss. J Urol 2004; 172: 976-9.

19 Garaffa G, Christopher AN, Ralph DJ. The management of genital lymphoedema. BJU Int 2008: 102: 408-14.

20 Lumen N, Monstrey S, Ceoulemans P, van Laeke E, Hoebeke P. Reconstructive surgery for severe penile inadequacy: phalloplasty with a free radial forearm flap or a pedicled anterolateral thigh flap. Adv Urol 2008; 2008: 704343.

21 Tran VQ, Lesser TF, Kim DH, Aboseif SR. Penile corporeal reconstruction during difficult placement of a penile prosthesis. Adv Urol 2008; 2008: 370947.

22 Bogoras N. Uber die volle plastische wiederherstellung eines zum Koitus fahigen Penis (peniplastica totalis). Zentralb/ Chir 1936; 63: 1271. German.

23 Gillies HD, Harrison RJ. Congenital absence of the penis with embryological consideration. Br J Plast Urol 1948: 1: 8.

24 Bettocchi C, Ralph DJ, Pryor JP. Pedicled pubic phalloplasty in females with gender dysphoria. BJU Int 2004; 95: 120-4.

25 Persky L, Resnick M, Desprez J. Penile reconstructionwith gracilis pedicled grafts. J Urol 1983: 129: 603-5.

26 Chang TS, Hwang WY. Forearm flap in one-stage reconstruction of the penis. Plast Reconstr Surg 1984: 74: 251-8.

27 Song R, Gao Y, Song Y, Yu Y, Song Y. The forearm flap. Clin Plast Surg 1982: 9: 21

28 Gilbert DA, Schlossberg SM, Jordan GH. Ulnar forearm phallic reconstruction and penile reconstruction. Microsurgery 1995: 16: 314-21.

29 Garaffa G, Christopher NA, Ralph DJ. Total phallic reconstruction in female to male transsexuals. Eur Urol 2010; 57: 715-22.

30 Garaffa G, Raheem AA, Christopher NA, Ralph DJ. Total phallic reconstruction after penile amputation for carcinoma. BJU Int 2009; 104: 852-6.

31 Selvaggi G, Monstrey S, Hoebeke P, Ceulemans P, van Landuyt K et al. Donor-site morbidity of the radial forearm free flap after 125 phalloplasties in gender identity disorder. Plast Reconstr Surg 2006; 118: 1171-7.

32 Doornaert M, Hoebeke P, Ceulemans P, Tsjoen G, Heylens G et al. Penile reconstruction with the radial forearm flap: an update. Handchir Mikrochir Plast Surg 2011; 43: 208-14.

33 Ma S, Cheng K, Liu Y. Sensibility following innervated free radial forearm flap for penile reconstruction. Plast Reconstr Surg 2010; 127: 235-41.

34 Hoebeke PB, Decaesteker K, Beysens M, Opdenakker Y, Lumen N et al. Erectile implants in female-to-male-transsexuals: our experience in 129 patients. Eur Urol 2010; 57: 334-40.

35 Ma S, Liu Y, Chang T, Cheng K. Long-term follow-up of sensation recovery of the penis reconstructed by Cheng's method. Plast Reconstr Surg 2010; 127: 1546-52.

36 Rubino C, Figus A, Dessy LA. Alei G, Mazzocchi M et al. Innervated island pedicled anterolateral thigh flap for neo-phallic reconstruction in female-to-male transsexuals. J Urol 1993; 150: 1093-8.

37 Papadopulos NA, Schaff J, Biemer E. The use of free prelaminated and sensate osteofasciocutaneous fibular flap in phalloplasty Int J Care Injured. 2008; 39: s62-7.

38 Felici N, Felici A. A new phalloplasty technique: the free anterolateral thigh flap phalloplasty. J Plast Reconstr Aesthet Surg 2006; 59: 153-7.

39 Garaffa G, Raheem AA, Ralph DJ. An update on penile reconstruction. Asian J Androl 2011; 13: 391-4.

40 Garaffa G, Ralph DJ, Christopher N. Total urethral construction with the radial artery based forearm free flap in the transsexual. BJU Int 2010; 106: 1206-10. 